\title{
SURFACE TOPOGRAPHY OF TWO TREMATODES PARASITES INFECT- ING GREY HERON ARDEA CINEREA JOUYI (AVES, CICONIIFORMES) IN QENA, EGYPT By
}

KHALAF NOUR ABD EL-WAHED AMMAR

Department of Zoology, Faculty of Science; South Valley University, Qena, Egypt.

\begin{abstract}
Apharyngostrigea ardeolina and Echinoparyphium recurvatum are two important digenean parasites that were recovered from small intestine of grey heron with an infection rate $(16.2 \%)$ and $(8.8 \%)$ respectively. The surface topography of two species was redescribed by both light and scanning electron microscopy.

Using SEM studies showed that the body surface of two trematodes were covered by contact receptors, several types of sensory tegumental papillae which may have useful function in orientation and feeding through increasing the surface area of absorption, could also play a role in sensation or in selection of the materials for ingestion by the fluke .

The head collar of E. recurvatum is reniform in shape, bearing uninterrupted double row of 41 collar finger-like spines, a total including 4 end group ones on both ventral corners., tegumental spines were tongue-shaped without a terminal tip,

Key words: Egypt, Aves, Ardea cinerea, SEM, Echinostomatidae, Strigeidae.
\end{abstract}

\section{Introduction}

The ardeid birds, commonly known as egrets and herons, belong to the order Ciconiiformes, generally inhabiting tropical and subtropical regions in mudflats, ponds, lakes, water reservoirs and dam areas, as well as wetlands; Heron play an important role in biological control of agricultural enemies such as, insects, mollusks, earth worms, fishes, reptiles and rodents in which many of them act as intermediate host for helminthes and also, many parasites from these birds act as a source of infection for domestic birds (Joseph, 1979).

Some ardeids can act as definitive hosts for some potential zoonotic helminth species, such as Phagicola angrense Travassos, 1916, also, may play a role in transmission of digenia from freshwater fish as Tilapia nilotica in Egypt (Abo Essa, 2000).

Wild birds are widely distributed due to their ability for adaptation to great climate variations, in an agricultural country like Egypt, man is usually in intimate contact with water, and hence there is a potential danger of infestation with parasites of birds Mahdy and El-Ghaysh, (1998).
Trematodes of the family Strigeidae Railliet, 1919 are mainly parasites of birds, Niewiadomska (2002) grouped the 13 genera belonging to this family into subfamilies according to host specificity; 12 genera included in Strigeinae Railliet, 1919 are parasites of birds and one, included in Duboisiellinae Baer, 1938 is reported in mammals (Lunaschi and Drago, 2006).

Echinostome is a common parasite of a big variety of hosts. Dawes (1946) and Yamaguti (1958) listed the parasite in many birds. In Assiute locality the parasite was described by El-Naffar\&Khalifa (1975) from Ardeola ibis ibis., several kinds of fresh water snails, and several species of frogs and their tadpoles were reported as the first and second intermediate hosts respectively of E. recurvatum in the world literature (Yamashita, 1964; Rim, 1982; Beaver et al, 1984).

E. recurvatum is an intestinal digenean of wild birds and mammals including humans (Sohn et al, 2011), and an old cosmopolitan species Skarjabin, 1947; Yamaguti, 1958. Human infections with this fluke have been reported in Taiwan, Indonesia and Egypt (Beaver et al, 1984). 
E. recurvatum in Korean wild birds was considered a new species named as E. koidzumii (Chu et al, 1973), but later regarded as a synonym of E. revolutum by Yamagyti (1933), and recently recorded from a house rat (Lee et al, 1990).

Echinostomiasis can cause severe epigastric and/or abdominal pain accompanied by diarrhea, easy fatigue, and malnutrition. Heavy worm loads may lead to death due to intestinal perforation or marked malnutrition and anemia, as has been reported for infection caused by an echinostome species, Artyfechinostomum malayanum (under the name Artyfechinostomum mehrai), in India (Chai, 2009).

Studies of the surface ultrastructures of trematodes is often helpful for discovering their taxonomic significance, and gives a clue to the understanding of their morphological, the interactions between the parasite and its environment occur through the tegument (Chung et al, 1992).

\section{Materials and Methods}

In this study a total of 38 birds captured from Qena province then dissected and the alimentary tract was separated Intestinal mucosal scrap as well as the contents were washed several times with physiological saline, and after sedimentation, the sediments were examined under dissecting microscope for parasites.

The isolated parasites were washed in saline solution and fixed in 10\% buffered formalin. Specimens were stained in AceticCarmine, dehydrated and mounted in Canada balsam. Drawings were made with the aid of a Camera Lucida.

For SEM studies, recovered species were washed in phosphate buffered saline and fixed overnight in $2.5 \%$ gluteraldehyde $(\mathrm{PH}$ $7.4)$ at $4^{\circ} \mathrm{C}$. Specimens were washed three times in phosphate buffer and post fixed in $1 \%$ Osmium tetraoxide in $0.1 \% \mathrm{M}$ Phosphate buffer and dehydrated through a graded series of ethanol. Complete dehydration was performed in two changes of absolute ethyl alcohol. Specimens were then mounted on stubs with double adhesive tape, coated with gold. The samples were examined with a high resolution scanning electron microscope (Joel 1200 Ex II).

\section{Result}

Total of 38 grey heron were collected in Qena Governorate, from May to October 2010. 26 of these showed the presence of parasites. The infection degree was $(68.4 \%)$. The parasitic trematodes were Apharyngostrigea ardeolina in 12 herons (16.2\%); Echinoparyphium recurvatum in only two (8.8\%).

Apharyngostrigea ardeolina Vidyarthi, 1937: Plate (1a,c., 2) Strigeidae Railliet, 1919:

Descriptive morphology: Fresh specimens often curled themselves into a $\mathbf{U}$ or comma shape, body elongated showing curvature or slightly bent bi-segmented and stretched, $6.1-8.1 \mathrm{~mm}$ in length. Fore body cup shaped to cylindrical $2.3-3.1 \times 1.1-1.4 \mathrm{~mm}$ wide; hind body sub cylindrical, 3.8-5.1x0.64- $0.79 \mathrm{~mm}$ wide, usually narrower than fore body, Length ratio of hind body to fore body, 1.7:1. Oral sucker marginal 0.17- $0.26 \times 0.17$ $0.23 \mathrm{~mm}$, lacking pharynx, Acetabulum (ventral sucker) cup-shaped, slightly preequatorial $0.23-0.38 \times 0.26-0.34 \mathrm{~mm}$, distinctly larger than oral one. Tribocytic organ (to) well-developed; dorsal lobe of anterior end located at posterior end level of oral sucker and ventral lobe located at anterior region level of acetabulum. Proteolytic gland (pg) large, $0.5-0.7 \times 0.3-0.4 \mathrm{~mm}$. Hind body subcylindrical, wide in region of testes. Testes tandem, located in posterior half of hind body; irregularly lobed, constricted at median portion; anterior testis $0.6-0.8 \mathrm{~mm}$ long, $0.5-0.7 \mathrm{~mm}$ thick and about $0.75 \mathrm{~mm}$ wide; posterior testis $0.7-1.010 \mathrm{~mm}, 0.49-0.74 \mathrm{~mm}$ and $0.80 \mathrm{~mm}$ respectively. Each testis multilobed with many irregular indentations. Seminal vesicle sinuous convoluted behind posterior testis. Genital cone (gc) welldeveloped. Ejaculatory duct connecting with uterus in genital cone, forming short hermaphroditic duct (hd). Ovary rounded with 
some incisions, $0.24-0.36 \mathrm{~mm}$ long, 0.23 $0.35 \mathrm{~mm}$ thick and $0.28-0.31 \mathrm{~mm}$ wide, with concavity directed postero-dorsal, pre-testicular, situated at junction of first \& second thirds of hind body. Seminal receptacle median or sub-median behind ovary. Vitelline follicles variably developed, most densely in region between proteolytic gland and ovary, less so posteriorly, reaching to near posterior end of body, and anteriorly, failing to reach ventral sucker in most specimens or extending somewhat beyond it in a few; vitelline reservoir and shell gland inter-testicutar. Oviduct starts from concaved portion of ovary and swollen between ovary and anterior testis forming ootype, eggs oval, operculated, 0.075-0.084x0.052-0.061 $\mu \mathrm{m}$ wide.

Premature stage present, body distinctly bi-segmented elongated stretched or slightly bent measuring $2.59 \mathrm{~mm}$, fore body cup shape to cylindrical, $0.94 \times 0.52 \mathrm{~mm}$ wide, hind body, sub-cylindrical $2.1 \times 0.38 \mathrm{~mm}$ wide always narrower than fore body, few number of sensory papillae present, without spines.

The SEM revealed that body surface exhibits annular furrows, ridges and sensory papillae without spines, and tegument reticulate and wrinkled.

Echinoparyphium recurvatum Luhe, 1909. Plate (1, b, d., 3). Echinostomatidae Loos, 1902.

Adult fluke with morphological characters of genus Echinoparyphium as given by Yamaguti. (1958). possessing a short uterus with few eggs; vitellaria in form of a small follicles not extending ovary.

Descriptive morphology: Adult worms elongated and anteriorly attenuated, measured 4.3-5.9. mm. Anterior end elongated and rounded, but posterior one attenuated. Anterior part from oral to ventral suckers slightly curved ventrally. Head crown well developed, armed with 41 retractable, horse-shoe shaped collar spines consisting of 33 spines of unequal size arranged into two rows, orally and aborally respectively, four spines each lateral or arranged on each corner, measuring 53-59 x58-60 $\mu \mathrm{m}$. Oral row spines smaller than aboral row ones. Oral sucker relatively small subterminal, 170-260x150-250 $\mu \mathrm{m}$ wide. Mouth cavity in oral sucker followed by a short prepharynx, a muscular pharynx, a large esophagus bifurcates in front of cirrus sac and ceca extend nearly to posterior end. Cirrus sac well developed with a saccular seminal vesicle.

Pre-pharynx up to 230 long, pharynx 90$150 \times 110-156 \mu \mathrm{m}$ wide. Oesophagus about $450 \mu \mathrm{m}$ long, Acetabulum in anterior fifth of body, 450-650x470-660 $\mu \mathrm{m}$ wide. Genital pore ventrally located, distant from anterior margin of ventral sucker. Testes tandem, at mid-hind body, smooth, oval; anterior testis $230-500 \times 250-520 \mu \mathrm{m}$ wide; posterior testis $270-580 \times 210-520 \mu \mathrm{m}$ wide. Small ovoid cirrus sac extending postero-dorsally from genital atrium to middle of acetabulum with coiled internal seminal vesicle, paraprostatica and unspined cirrus. Ovary spherical, at or anterior to mid-body, 200-450 $\mu \mathrm{m}$ in diameter. Uterus intercaecal, opening into genital atrium through metraterm. Vitelline follicles lateral, dorsal and ventral to caeca, extending from near level of posterior margin of acetabulum to short distance from posterior end of body.

High magnification revealed body entire surface transversely deeply wrinkled, covered with cobblestone-like cytoplasmic processes and two types of spine tongue like shape in anterior part and tapering spines in posterior end. Rim of ventral sucker with a wrinkled, muscular border and numerous, randomly distributed, domed and small sensory papillae, sparsely distributed immediately posterior to ventral sucker, claw shaped tegumental spines. Velvety teguments on vertical groove, between oral and ventral suckers..

At posterior part of anterior body half surface, irregularly distributed sensory papillae. Tegument of mid-ventral surface flat, with severe transverse rows of folds. Tegument of posterior end wobble-stone-like, 
with only traces of spines. A total of 41 collar spines including 4 end group ones on both ventral corners alternately arranged in 2 rows. Tegumental spines finger-shaped lacked a terminal tip.

Consequently, it is confirmed that the surface ultrastructure of $E$. recurvatum was generally similar to that of other echinostomatid flukes. However, some features, i.e., morphological change of tegumental spines and appearance of sensory papillae on ventral sucker, number, shape and arrangement of collar spines, which might be of significance taxonomic and biological characteristic.

\section{Discussion}

In the present study, the two parasites infection rate was $(68.4 \%)$ that was higher than that reported by Ohbayashi (1967); Hassan and Abdel-Aal (1999), Sohn et al. (2002) and Farahnak et al. (2004). Their recorded rates were $14.9 \%, 13.7 \%, \& 18 \%$ respectively. The difference might be due to variation in localities or seasonal materials collection.

In the present study, Apharyngostragia ardeolina was characterized size and presence of a partial swelling of oviduct, which agreed with $A$. ardeolina Vidyarthi, 1937. However, rhe present species differed from A. ramai (Odening, 1963) and A. ibis (Hassan and Abdel-Aal, 1999) in the body length, length proportion between hind- and forebody and sizes of various organs especially proteolytic gland. As to E. recurvatum, there are two other Echinoparphyium species of similar species size; E. aconiatum and E. elegans (Yamaguti, 1958).

Buscher (1978) reviewed the genus Echinoparyphium with rising of E. speotyto as a new species. He allotted six species in Echynoparyphium group having 45 collar spines, and distinguished by the vitellaria distribution in E. recurvatum and E. morduilkoi, as in E. morduilkoi vitellaria extend anteriorly to ventral sucker posterior edge, while in E. recurvatum vitellaria extend from uterus posterior $1 / 3$ level to the body posterior end.

In Egypt, two echinostome species possessing 43-collar-spines (Moravec et al, 1975) E. recurvatum and Lie et al. (1975) reported its taxonomic morphology and life cycle. There was only one species of Echinoparyphium on record with the number of collar spines close to 25, E. jubilarum from a Eurasian kestrel, Falco tinnenculus, with a size not less than $4.5 \mathrm{~mm}$, with 27 collar spines and without body spines. However, E. jubilarum was finally included in genus Petasiger, subgenus Neopetsiger. Genus Petasiger possesses 27 collar spines, with four largest ones on each side from the corner spines, with the remainder decreasing in size towards median plane. Vitellaria follicles extend forward beyond ventral sucker and testes transversely ovoid or lobed and slightly flattened (Dawes. 1956). The loss of spines might be due to the decreased movement of the fluke within its host, but, still retains spines on surface, which implied more movement (Dangprasert et al, 2001). In the present specimens, head was crown, horseshoe shaped collar spines consisted of unequal spines in E. revolutum most probably aid in migration throughout the intestinal mucosa. This finding agreed with Benjamin and James (1987) and Russell-Pinto et al. (1996).

Generally, in many helminthes, body surface plays an important role in integrating the worm's physiology with its microenvironments via nutrient assimilation, regulation of internal chemical pools by selective absorption or secretion mechanisms and chemosensory activity (Hayunga, 1991).

SEM tegumental structure study, added to the systematic position, structures and the taxonomic status of the parasite to group of new members (Ammar, 2008).

In the present study, SEM studies showed that the body surface of both trematodes were covered by contact receptors, several types of tegumental papillae between the spines, which may have useful function in 
orientation and feeding through increasing the surface area of absorption, and could also play a role in sensation or in selection of the materials for ingestion as in the paramphistome Zygocotyl linata (Irwin and Fried, 1994). Tegumental furrows and ridges were seen in several body regions, both in the forebody and hindbody in A. ardeolina, which might result from contraction during fixation and dehydration. Studies in other species, however, showed that similar furrows and ridges were related to the body wall contractility, a capacity which increased by the reticular structure of the tegument (Abidi et al, 1988). Besides, the tegument reticular nature effectively increased the worm surface area and consequently, the area available for the micronutrients absorption (Parkening and Johnson, 1969; Nollen et al, 1973; Nadakavukaren and Nollen, 1975; Abidi et al, 1988). Such a mechanism for increasing the surface area of the body would be beneficial in large, stout worms, which have a much lower surface/volume ratio than smaller species.

Fried (1997) suggested that the trematode external surface of tegument spines might have other properties besides being absorptive, such as immunological protection. However, the others can play an important role in assuring the maintenance of the worms in their microhabitat and assistance in retaining the position of the parasite within its host and mechanical stimulation of the host tissue for feeding purposes.

In the present study, sensory papillae were distributed on the oral sucker lip, and grouped ciliated papillae were around the oral sucker. Peg-like tegumental spines were densely distributed on the ventral sucker anterior surface level. The ventral sucker had an aspinous tegument and no sensory papillae. Tegumental spines on the posterior ventral sucker surface level were sparsely distributed and absent posteriorly; the tegument around the oral sucker was spines and wrinkled concentrically. The ventral sucker had a wrinkled tegument and many bulbous papil- lae. Sensory papillae were distributed between the bulbous papillae. Tegumental spines were spade-shaped with a terminal tip. A total of 41 collar spines including four end group ones on both ventral corners was alternately arranged in 2 rows. The tegumental spines were tongue-shaped without a terminal tip, from the above results, it is confirmed that the surface ultrastructure of E. recurvatum was generally similar to that of other echinostomatid flukes. The tegumental spines distribution may aid in the worms locomotion in the intervillous space of the definitive host intestines (Han et al, 2003).

\section{Conclusion}

The outcome results showed that the surface ultrastructure of E. revolutum is similar to that of other echinostomes, but unique in the number and arrangement of collar spines, shapes and tegumental spines distribution as well as type and distribution of sensory papillae.

\section{References}

Abidi, SMA, Ahamad, M, Nizami, WA, Hanna, REB, 1988: Clinostomum complanatum: tegumental surface changes during in vivo development. Int. J. Parasitol. 18:433-9.

Abo Essa, FJ, 2000: Role of fish eating bird Ibis ibis in transmitting some parasitis larval stages to freshwater Oreochromis niloticus fish. Egypt. J. Agric. Res. 78, 1:105-16.

Ammar, KHNA, 2008: Ultrastrucural sudy of some helminth parasites infecting the goatfish, Mullus surmuletus (Osteichthyes: Millidae) from Syrt coast, Libya. Egyptian-German Union of life Sci. Invert. Zool. 55D:169-88.

Bakke, TA, 1976: Shape, size and surface topography of genital organs of Leucochloridium sp. (Digenea), revealed by light and scanning microscopy. Z. Parasitenkd 51:99.

Beaver, PC, Jung, RC, Cupp, EW, 1984: Clinical parasitology. $9^{\text {th }}$ ed., Lea \& Febiger. Philadelphia, USA.

Begamin, LB, James, BL, 1987: The development of metacercaria of Maritrema lunguila Jag, 1908 (Digenea: Microphylidae) in the intermediate host Ligia oceanica (L). J. Parasitol. 94: 221-31. 
Buscher, HN, 1978: Echinoparyphium speotyto sp.n. (Trematoda:Echinostomatidae) from the burrowing owl in Oklahoma, with a discussion of the genus Echinoparyphium. J. Parasitol. 64: $52-8$.

Chai, JY, 2009: Echinostomes in humans. In: Fried B, Toledo R, editors: The biology of echinostomes. New York: Springer.

Chu, JK, Cho, YJ, Chung, SB, Won, BO, Yoon, MB, 1973: Study on the trematode parasites of the birds in Korea. Korean J. Parasitol. 22:705.

Chung, DI, Moon, CH, Kong, HH, Choi, DW, Lim, DK, 1995: The first human case of Clinostomum complanatum (Trematoda: Clinostomatidae) infection in Korea. Kor. J. Parasitol. 33, 3: 219-23.

Dawes, B, 1946: The trematodes with special references to British and other European forms. Cambridge University Press, Cambridge and Bentley house, London.

Dawes, B, 1956: The Trematoda. University Press, Cambridge, London.

Dangprasert, T, Khawsuk, W, Meepool, A, Wanichanon, C, Viyanant, V, et al, 2001: Fasciola gigantica surface topography of the adult tegument. J. Helminthol. 75:43-50.

El-Naffar, M, Khalifa, R, 1975: Parasitofauna of the Egyptian aquatic birds. 1- Trematode parasites of the buff-backed heron (Ardeola ibis ibis) in Assiut Governorate, Egypt. J. Egypt. Soc. Parasitol. 4/5:42-56.

Farahnak, A, Shiekhian, R, Mobedi, I, 2004: A faunistic survey on the bird helminth parasites and their medically importance. Iranian J. Publ. Hlth. 33, 3:40-6.

Fried, B, 1997: An overview of the biology of trematodes. In: Fried B, Graczyk TK (eds) Advances in Trematode Biology. CRC Press, New York.

Hassan, MG, Abdel-Aal, AA, 1999: Studies on helminth parasites infesting some wild birds in Suez Canal area and Sinai Peninsula. Assiut Vet. Med. J. 40, 80:103-18.

Hayunga, EG, 1991: Morphological adaptations of intestinal helminthes. J. Parasitol. 77: 865-73.

Han, ET, Kim, JL, Chai. JY 2003: Recovery, growth, and development of Acanthoparyphium tyosenense (Digenea: Echinostomatidae) in experimental chicks. J. Parasitol. 89:23

Irwin, SWB, Mckerr, G., Judge, BC, Moran, I. 1984: Studies on excystment in Himasthla leptosome (Tramatoda: Echinostomatidae) and newly emerged metacercariae. Int. J. Parasitol. 14:415-21.

Joseph, SA, 1979: Indian barn owl (Tyto alba javanica) as a new paratenic host for Spirocerca lupi (Rudolphi, 1809) Railliet and Henry, 1911. Cheiron. 8, 3:168-70.

Khalifa, R, El-Naffar, MK, 1983: Phaneropsolus sp. n. (Trematoda: Pleurogenidae) from birds of Upper Egypt, and remarks on representatives of the genus. Acta. Parasitol. Pol. 28:369-73.

Lee, SH, Sohn, WM, Chat, JY, 1990: Echinostoma revolutum and Echinoparyphium recurvatum recovered from house rats in Yangyang. gun. Kangwon-do.Korean J. Parasitol, 28:23540.

Lie, KJ, Mansour, N, Lee, HF, Kostanian, N, 1975: The life cycle of Echinoparyphium ralphaudyi sp.n. (Trematoda: Echinostomatides). J. Parasitol. 61, 1:59-65.

Lunashi, L, DRAGO, FB, 2006: Strigeid parasites of the roadside hawk, Buteo magnirostris (Aves: Falconiformes), from Argentina. Zootaxa 1106:25-33.

Mahdy, AO, El-Ghaysh, A, 1998: Spoiruroid parasites of Buff backed heron (Ardeola ibis ibis) with a new species of Cordonema and Micrtetrameres together with a key to the genera of Acuaridae (Seurat, 1915). J. Egypt. Ger. Soc. Zool. 27D:73-89.

Moravec, F, Barus, V, Rysavy, B, Yousief, F, 1974: Observation on the development of two echinostomes, Echinoparyphium recurvatum and Echinostoma revolutum, the antagonists of human schistosomes in Egypt. Folia Parasitol. 21: 107-26.

Nadakavukaren, MJ, Nollen, PM, 1975: A scanning electron microscopic investigation of the outer surface of Gorgoderina attenuata. Int. J. Parasitol. 5:591-5.

Niewiadomska, K, 2002: Family Diplostomidae Poirier, 1886. In: Keys to the Trematoda. Vol. 1 Eds. DI, Gibson, A, Jones, RA, Bray. CABI Publishing and Natural History Museum, Wallingford.

Nollen, PM, Restaino, AI, Alberico, RA, 1973: Gorgoderina attenuata: up take and incorporation of tyrosine, thymidine andadenosine. Exp. Parasitol. 33:468-76.

Odening, K, 1963: Strigeida arts Vgeln des Berliner Tierparks. Angew. Parasitol. 4:171-42.

Ohbayashi, M, 1967: Gryporhyvchus nycplcoracis Yamaguti, 1956 (Dilepididae; Cestoda) 
and Apharyngostragia ardeolina Vidyarthi, 1937 (Strigeidae; Trematoda) from Ardea cliverea Jouyiclark Hokkaido University.

Parkening, TA, Johnson, AD, 1969: Glucose uptake in Haematoloechus medioplexus and Gorgoderina trematodes. Exp. Parasitol. 25:358-67.

Rim, HJ, 1992: Echinostomiasis. CRC Handbook Series in Zoonoses. Section C: Parasitic Zoonoses. Vol III, CRC Press, Boca Raton, Florida, USA.

Russel-Pinto, F, Owers, EB, James, B, 1996: Ultra structure study of the intramolluscan stages of Meiogymnophallus minutus (Digenea: Gymnophyllidae) in Scrobicularia plana from Portugal, (Bivalvia). Parasitol. Res. 82:428-34.

Sohn, WM., Woo, HC, Hong, SJ, 2002: Tegumental ultrastructures of Echinoparyphium recurvatum according to developmental stages. Korean J. Parasitol. 40:67-73.

Sohn, WM, Jong, YC, Tai, SY, Keeseon, SE, Cheong, HY, et al, 2011: Echinostoma revolu- tum Infection in Children, Pursat Province, Cambodia. Gov/Edi. 17:1.

Skarjapin, KL, 1947: Trematodes of animals and man. Vol 1: Fundementals of Terminology. Moscow (translated into English by USDA).

Stunkard, HW. 1938: The morphology and life cycle of the trematode Himasthla quissetensis (Miller and Northup, 1926). Biol. Bull. 131:14564.

Travassos, L, 1917: Contribuição para o conhecimento da fauna helmintológica brasileira VI. Revisão dos acantocéfalos brasileiros. Part I. Family Giganthorhynchidae Hamman, 1892. Mem. do Inst. Oswaldo Cruz, 9:1-62.

Yamaguti, S, 1933: Studies on the hetminth fauna of Japan Part 1. Trematodes of birds, reptiles and mammals. Jpn. J. Zool. 2:1-134.

Yamaguti, S. 1958: Systema Heminthum. Vol. I; The Digenetic Trematodes of Vertebrates.

Yamashita, J. 1964: Echinostome. Prog Med. Parasite in Japan 1:288-313.

\section{Explanation of plates}

Plate 1: Camera Lucida drawing (a) Apharyngostregia ardeolina showing curvature body shaped., acetabulum (a) cup-shaped, slightly pre-equatorial, Tribocytic organ (to) well-developed, Proteolytic gland (pg) large, (c) posterior end illustration genital cone (gc) well-developed with nephroditic duct, Ejaculatory duct connecting with uterus in genital cone, forming short hermaphroditic duct (hd). (b) Echinoparyphium recurvatum showing elongated body ,acetabulum higher than oral sucker., (d)high magnification of head collar illustration 41 spines consisting of 33 spines of unequal size arranged into two rows, orally and ab orally, four spines were each lateral or grouped on corner.

Plate 2: SEM micrographs Apharyngostregia ardeolina (c) body curvature and bent,(a) Oral sucker marginal., (b) premature stage (e) annular furrow, tegument reticulate and wrinkled.,( $\mathrm{f}$ ) muscular oral sucker, $(\mathrm{d}, \mathrm{g})$ small irregularly scattered papillae.

Plate 3: SEM micrographs Echinoparyphium recurvatum (b) ventral view of the adult worm showing large acetabulum (B) illustration lateral view of worm showing spines concentrated anterior third, (d)-magnified of acetabulum with transversely deeply muscular, wrinkled and covered with cobble-stone-like cytoplasmic processes, severe folds, (e) posterior end showing spines with excretory pore, (h)-broad finger like spine, (i)posterior end covered with cobblestone-like cytoplasmic processes and tapering spines (a,f) Head collar is reniform in shape, bearing uninterrupted double row of finger-like spines. 
Plate 1: Camera Lucida drawing (a) Apharyngostregia and (b) Echinoparyphium recurvatum

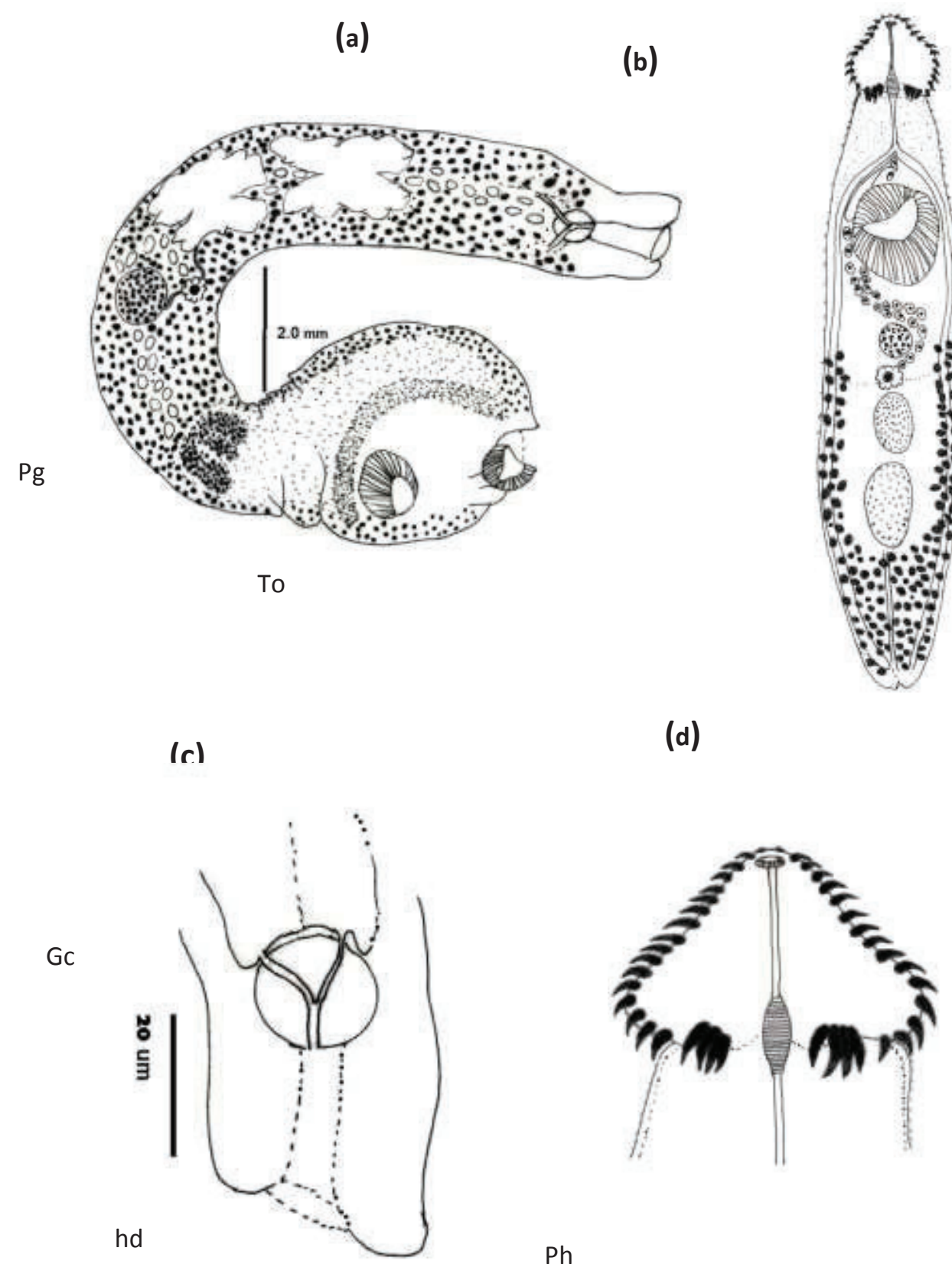




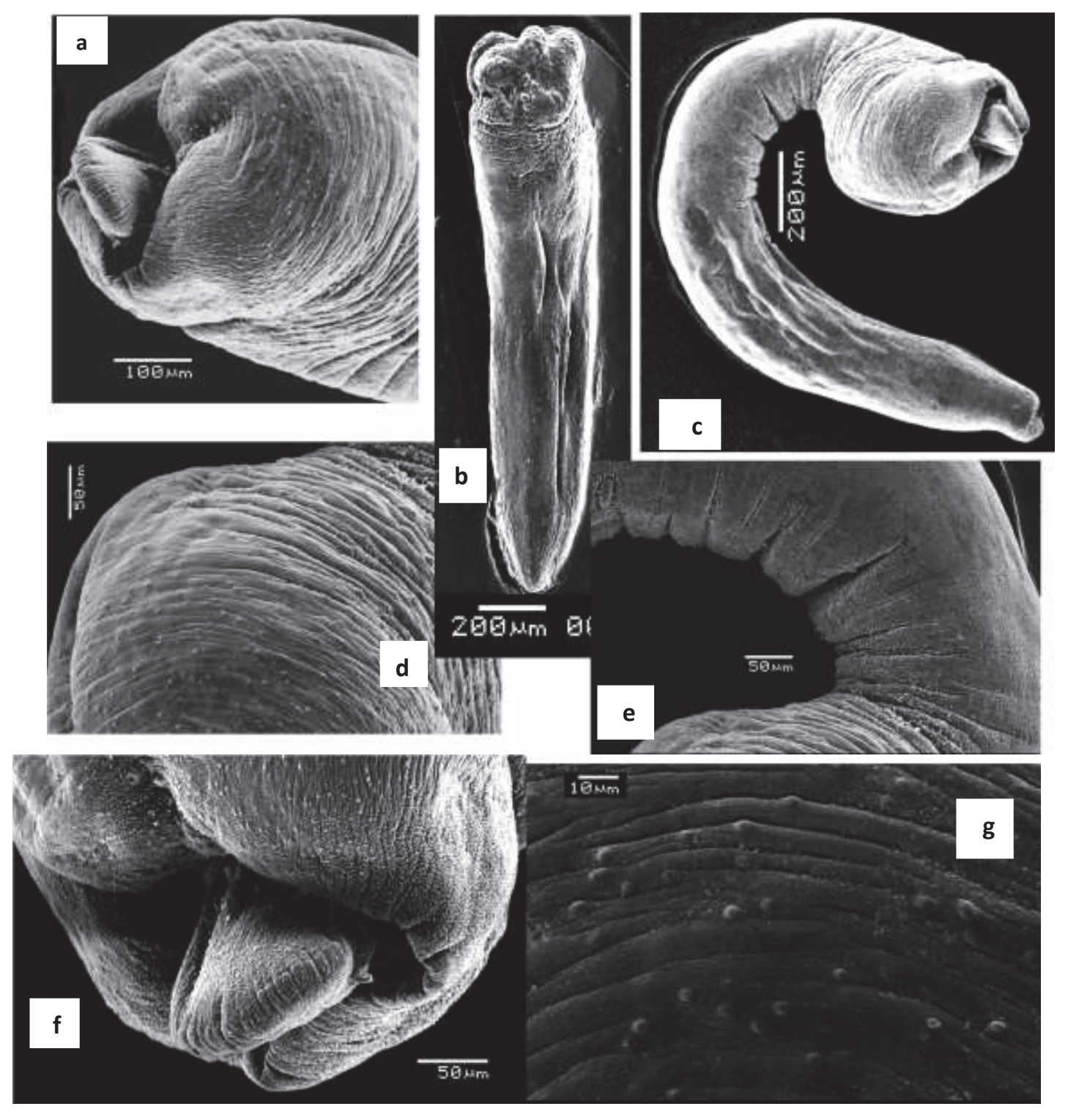

Plate (2): SEM micrographs Apharyngostregia ardeolina 


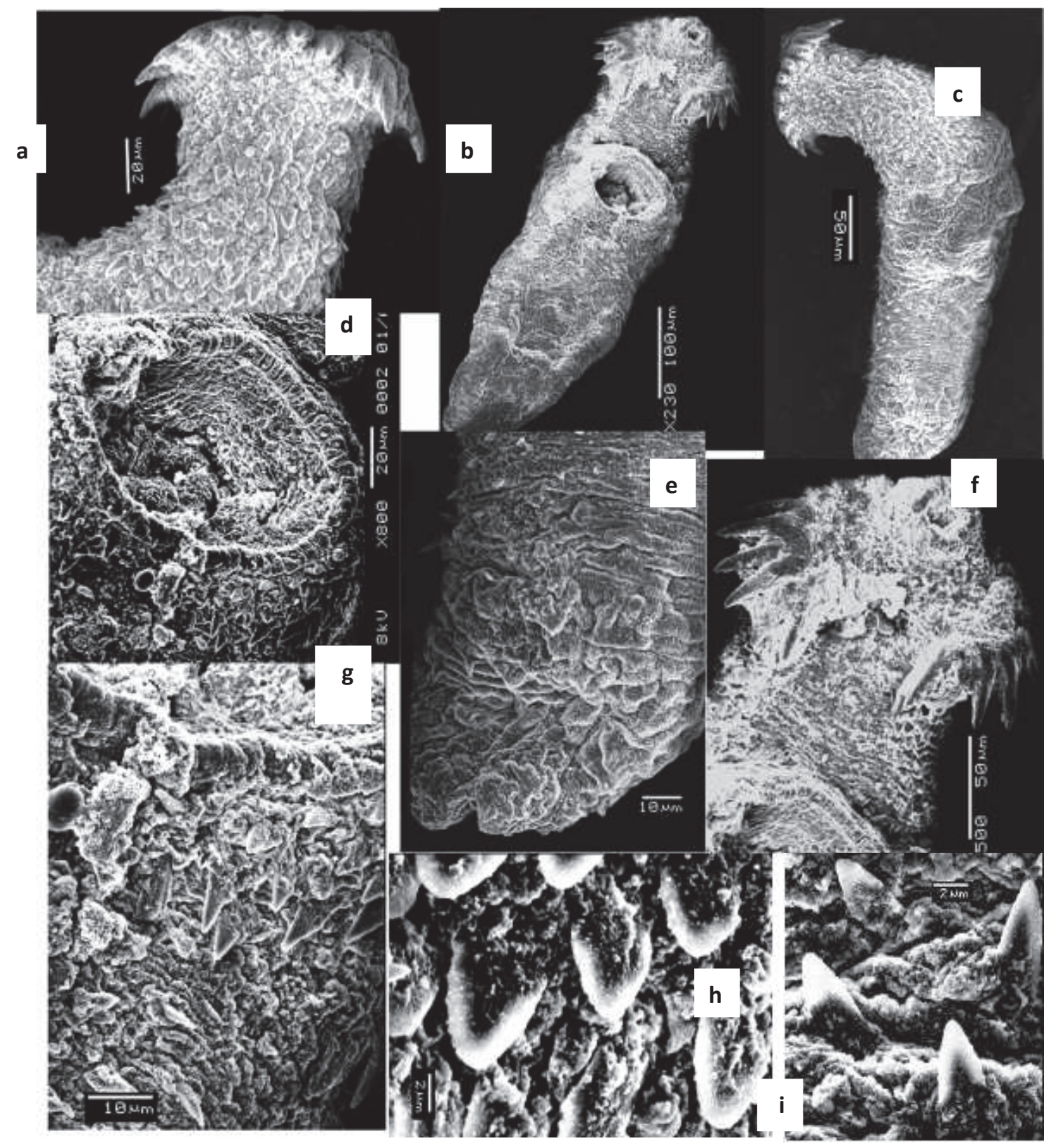

Plate 3: SEM micrographs Echinoparyphium recurvatum 